\section{ambient SCIENCE \\ Vol. 04(Sp1):12-15 \\ Year 2017}

\title{
Dignity-centered Care Model: an Attempt to Maintain Mutual Dignity Between the Patient and the Health System
}

\section{Raziyeh Ghafouri}

Student Research committee, School of Nursing and Midwifery, Iran University of Medical Sciences, Tehran, Iran

Study Area: Tehran, Iran

Coordinate: $29^{\circ} 29^{\prime} 47^{\prime \prime} \mathrm{N} 60^{\circ} 51^{\prime} 46^{\prime \prime} \mathrm{E}$

Key words: Hybrid Model, Human behaviour, Intrinsic dignity, Mental satisfaction

\begin{abstract}
Dignity-centered care model has recently attracted attentions in the literature. The International Council of Nurses emphasizes the provision of dignity-centered care coupled with ethic, and the World Health Organization asserts that access to dignif ied care must get an upper hand in the world. The present study aims to propose a model for dignity-centered care. In this study, a hybrid model was used as the research method. The research protocol included literature review, field study, analysis, and model development strategy. Dignity-centered care is associated with the maintenance of mutual dignity between the patient and the health system. We found, by maintaining mutual dignity between the patient and care providers, dignity-centered care increases mutual trust and satisfaction, mutual understanding, effective communication and also improves the quality of caretaking.
\end{abstract}

dignity and respectful behavior, few studies have been conducted on the process of dignity-centered care and its concepts have remained unknown (Schwartz-Barcott et al., 2002). Hence, the present study aims to provide a model of dignity-centered care using a hybrid method.

The hybrid model for concept development is one of the methods of conceptual evolution and theorizing. This model aims to resolve the ambiguity of concepts and studies a concept in its relevant context. In addition, this method brings it possible to propose a model through achieving a deeper and more complete understanding of the concept in the context of the study and identifying the relationship between features, effective factors, antecedents, and implications of the desired concept (Bousso et al., 2009).

\section{Methodology:}

The present study was based on a hybrid model. In this method, firstly the desired concept was proposed in three steps of literature view, field study, and analysis and then the model was developed through one of the three strategies of choice, consensus, and creation. In the present study, the creation strategy was used for model development. According to this strategy, after identifying the features, antecedent, and implications of the concept, the factors affecting the concept were extracted and then

*Author:ghafouri.r@tak.iums.ac.ir 
the model statements were developed by completing the relationship between concepts. Finally, the model was developed by organizing the concepts and statements (Schwartz-Barcottetal., 2002).

Literature review: keywords as; dignity-centered care, patient dignity, dignity in the health system, care, and dignity were searched on PUBMED database and 143 articles were obtained. After removing the duplicates, 112 articles were selected for the study. Then, the abstracts of the articles were analyzed in terms of the inclusion criteria and 65 articles were selected. In the next step, out of the selected

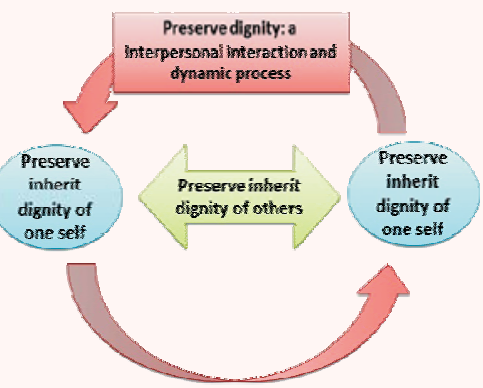

Figure 1: The pattern of dignity maintenance articles, 31 Persian or English articles based on dignitycentered care published in the period 1990-2017 were selected for finally analyses. Fig.-1 shows the process of articles selection. The data were analyzed by using the content analysis method (Elo \& Kyngäs, 2008) in order to identify the features, antecedents, and implications of the desired concept. The articles relevant to features, antecedents, and implications of dignity-centered care have been presented in Table 1.

Table 1: Articles relevant to features, antecedents, and implications of dignity-centered care

\begin{tabular}{lll}
\hline Category & Concept & Articles \\
\hline Features & $\begin{array}{l}\text { Interpersonal } \\
\text { process }\end{array}$ & $\begin{array}{l}\text { Gallagher, 2004; Lam, 2007; } \\
\text { Johnston } \text { et al., 2012 }\end{array}$
\end{tabular}

Antecedents Respect

Michael, 2014; Jackson \& Irwin, 2011; Lam, 2007; Lohne et al., 2014; Kwak \& Lee, 2013; Baertschi, 2014

Implications Mutual understanding (empathy)

Jackson \& Irwin, 2011; Lam, 2007; Ho et al., 2013; Hamooleh et al.,

Sense of mutual trust 2013; Baillie,2009; Necek, 2014

Sense of Jackson \& Irwin, 2011; Baillie, 2009; Lohne et al., 2014 satisfaction (worthwhileness)

Effective Jackson \& Irwin, 2011; Baillie, communication 2009; Johnston et al., 2012; Stoecker, 2014

A literature review has concluded that dignity-centered care is associated with the maintenance of mutual dignity between the patient and the health system. Dignitycentered care is an interpersonal process whose most important antecedent is the maintenance of intrinsic dignity, that is realized through mutual respect, and its outcomes include increased trust and satisfaction, mutual understanding, and effective communication also and improved the quality of care.

Field study: the data were collected by using qualitative approaches (Bousso et al., 2009; Schwartz-Barcott et al., 2002). The required data were collected and analyzed through semi-structured interviews. We included 3 nurses, 3 physicians, and 3 patients for interviews. After each interview, recorded data were transcribed, analyzed using the conventional content analysis method, and finally organized with MAXQDA 10.

The interviewees emphasized the indiscriminate maintenance of mutual respect. For example, one of them stated, "We should not insult or disrespect others just because having a higher position or more work experience". Another interviewee, emphasizing the mutuality of dignity maintenance, said, "This is a two-way process. I should respect the dignity of others and then I can expect them to respect my dignity. This is also true in the relationship between patients and the medical staff. Any of them who do not respect the dignity of the other side cannot expect other to do so." In terms of implications, interviewees stated that observance of mutual respect and dignity leads to mutual understanding, increased satisfaction and trust, and effective communication.

\section{Results:}

At the stage of integration and analysis, common points of data obtained from the first and second stages were identified and the findings of both stages were integrated (Bousso et al., 2009). Comparison of the results of the two stages in this study showed that maintaining dignity is a two-way interactive process that results in mutual understanding, increased satisfaction and trust, and effective communication.

Analysis of the concept of dignity-centered care model: by integrating the data obtained from two stages of literature review and field study, we attempted to identify the main concepts and the relationship between them. Further, the relationship between concepts was completed and the model statements were developed by identifying the factors affecting this concept and considering the relevant features, antecedents, and implications. Finally, these concepts and statements were organized to develop a dignity-centered care model.

The study findings revealed that dignity-centered care is an interpersonal process and maintenance of mutual dignity ensures its stability. Developed based on the study findings, Fig.-1 shows that dignity maintenance is an interpersonal process and maintaining the inherent dignity of oneself and others cause its stability and continuity. 


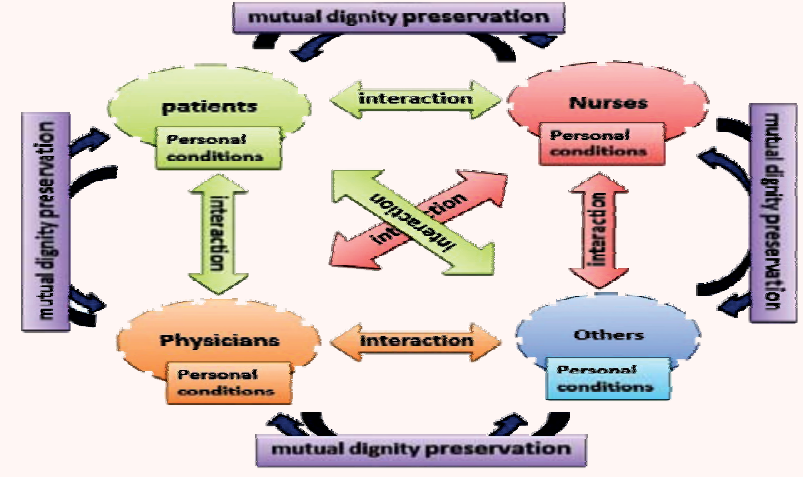

Figure 2: The pattern of maintaining mutual dignity between individuals in the process of care (dignity-centered care)

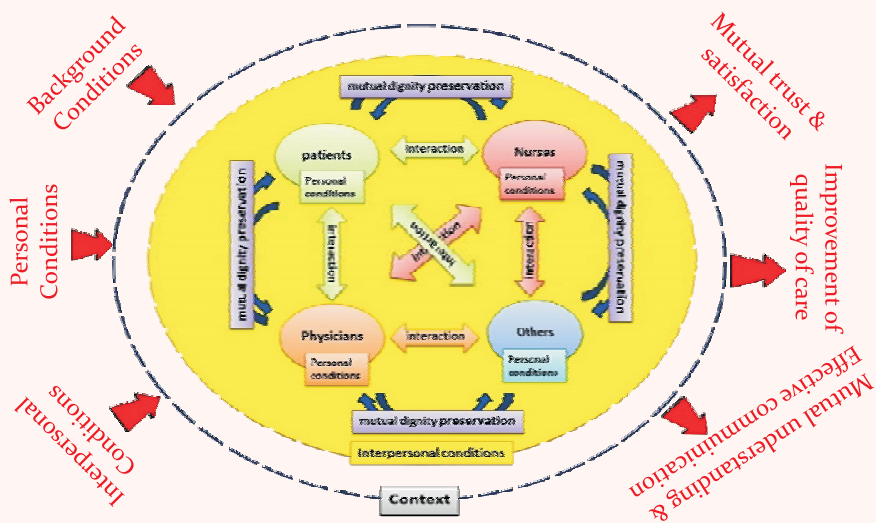

Figure 3: Dignity-centered care model with regard to factors affecting it and also its features and implications

In the process of care, the patients are in contact with the staff appointed for the health system, and, in fact, they have an interpersonal communication network with health system staff which includes nurses, physicians, paramedics, etc. Conditions of each of these individuals affect and the relationship between them affect the whole network. To achieve dignity-centered care in all interactions, it is necessary to maintain mutual dignity. Figure 2 shows the process of maintaining mutual dignity between patients and the health staff.

\section{Discussion:}

Dignity-centered care is associated with the maintenance of mutual dignity between the patient and the health system. Dignity-centered care is an interpersonal process whose most important antecedent is the maintenance of intrinsic dignity, that is realized through mutual respect, and its outcomes include increased trust and satisfaction, mutual understanding, and effective communication also and improved the quality of care.

Michael (2014) states that dignity is a common concept in society and involves items such as human rights and medical ethics. He identified two levels of inherent and non-inherent dignity. Maintaining inherent dignity involves equality of all people to all ethical issues independent of conditions. Maintaining inherent dignity is one of the primary principles of human rights, especially in the right to freedom and equality. These are consistent with the findings of the present study.

Baillie (2009) argued that human dignity includes feelings (sense of calm in control and values) reflect in mutual behavior. The environment, behavior of nurses, and characteristics of patients, including age and behavior, influence human dignity, and failure to comply with privacy is a threat to human dignity. These results also corroborate the findings of the present study. Sabatino et al. (2014) asserted that individual characteristics and environmental elements are two main dimensions of dignity maintenance. The results of the present study also indicated that individual characteristics and environmental factors were effective on the maintenance of dignity.

Tranvag et al. (2014) stated that three main dimensions of patient dignity include previous dignity experiences, individual dignity, and interpersonal dignity. Chochinov et al. (2002) stated that the main classes of the concept of dignity are "concerns about the disease", "disrespect for dignity", and "social dignity interventions". The findings of these studies also indicate that mutual respect is a pivotal element in dignity-centered care, and personal and interpersonal factors and underlying conditions affect it.

Hack et al. (2010) believed that dignified behavior includes an effective approach to the reduction of sufferings, quality improvement, and enhancement of the sense of dignity in dying patients, which lead to the provision of a safe and effective treatment environment. Lohne et al. (2014) stated that maintaining dignity means to treat others the same you with they treat you. In addition, Jackson \& Irwin (2011) reiterates that dignified behavior is necessary at all stages of providing care even after death and dignified behavior of nurses towards patients results in the sense of worthwhileness, sense of usefulness, trust, and freedom in decision-making. The present study strengthened the findings of abovementioned studies in terms of the implications of dignitycentered care. Conclusively, by maintaining mutual dignity between the patient and care providers, dignitycentered care increases mutual trust and satisfaction, mutual understanding, and effective communication and also improves the quality of provided care.

\section{Recommendations:}

Since dignity-centered care was defined in this study and the factors affecting it was identified, the present study can be a basis for further research in this regard with more and more participations of the subjects (interviewees) and also be dealing with issues related to dignity-centered care. 


\section{Acknowledgements:}

The present paper was extracted from a research project (95-01193-280o9) approved by Student Research Committee of Iran University of Medical Sciences. The authors would like to thank all staff of this center who helped us in this research.

\section{References:}

Baertschi, B. (2014): Human dignity as a component of a longlasting and widespread conceptual construct. J. Bioeth. Inq., 11(2): 201-211.

Baillie, L. (2009): Patient dignity in an acute hospital setting: a case study. Int.J.Nurs. Stud., 46(1):23-36.

Bousso, R.S., Poles, K. \& Rossato, L.M. (2009): Concept development: new directions for research in thanatology and nursing. Rev. EsC. Enferm. USP, 43 (2): 1331-1336.

Chochinov, H.M., Hack, T., Mcclement, S., Kristjanson, L. \& Harlos, M. (2002): Dignity in the terminally ill: a developing empirical model. Soc. Sci. Med., 54(3):433-43.

Elo, S. \& Kyngäs, H. (2008): The qualitative content analysis process. L. Adv. Nurs., 62(1):107-115.

Gallagher, A. (2004): Dignity and respect for dignity-two key health professional values: implications for nursing practice. Nurs. Ethics, 11(6):587-599.

Hack, T.F., Mcclement, S.E., Chochinov, H.M., Cann, B.J., Hassard, T.H., Kristjanson, L.J. \& Harlos, M. (2010): Learning from dying patients during their final days: life reflections gleaned from dignity therapy. Palliat. Med., 24(7), 715-723.

Hamooleh, M.M., Borimnejad, L., Seyedfatemi, N. \& Tahmasebi, M. (2013): Perception of Iranian nurses regarding ethicsbased palliative care in cancer patients. J. Med. Ethics Hist. Med., 6:12.

Ho, A.H., Leung, P.P., Tse, D.M., Pang, S.M., Chochinov, H.M., Neimeyer, R.A. \& Chan, C.L. (2013): Dignity amidst liminality: healing within suffering among Chinese terminal cancer patients. Death Stud., 37(10): 953-70.
Jackson, A. \& Irwin, W. (2011): Dignity, humanity and equality: Principle of Nursing Practice A. Nurs. Stand., 25(28):35-37.

Johnston, B., Ostlund, U. \& Brown, H. (2012): Evaluation of the Dignity Care Pathway for community nurses caring for people at the end of life. Int. J. Palliat. Nurs., 18(10):483-489.

Kwak, S.Y. \& Lee, B.S. (2013): Experience in acceptance of hospice by patients with terminal cancer: a phenomenological research.J. Korean Acad. Nurs., 43(6): 781-90.

Lam, K.K. (2007): Dignity, respect for dignity, and dignity conserving in palliative care. HKSPM Newsletter, 3:30-35.

Lohne, V., Rehnsfeldt, A., Raholm, M. B., Lindwall, L., Caspari, S., Saeteren, B., Hoy, B., Lillesto, B., Heggestad, A. K., Slettebo, A., Aasgaard, T. \& Naden, D. (2014): Family Caregivers' Experiences in Nursing Homes: Narratives on Human Dignity and Uneasiness. Res. Gerontol. Nurs., 7(6):265-272.

Michael, L. (2014): Def ining dignity and its place in human rights. New Bioeth., 20(1):12-34.

Necek, K.R. (2014): The dignity of older persons in view of postconciliar church teaching. Przegl. Lek., 71(1):57-60.

Sabatino, L., Stievano, A., Rocco, G., Kallio, H., Pietila, A.M. \& Kangasniemi, M.K. (2014): The dignity of the nursing profession: A meta-synthesis of qualitative research. Nurs Ethics. 21(6):659-672.

Schwartz-Barcott, D., Patterson, B.J., Lusardi, P., and Farmer, B.C. (2002): From practice to theory: Tightening the link via three fieldwork strategies. J. Adv. Nurs., 39(3): 281-289.

Stoecker, R. (2014): Philosophy of human dignity and the ethics of psychiatry. Psychiatr. Prax., 41 (Supp.-1), S19-25.

Tranvag, O., Petersen, K.A. \& Naden, D. (2016): Crucial dimensions constituting dignity experience in persons living with dementia. Dementia, 15(4):578-595. 